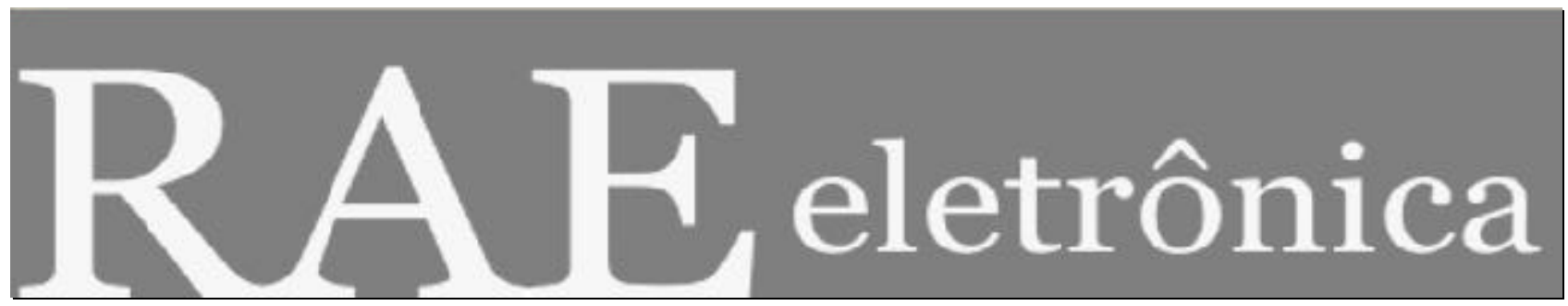

\title{
PERCEPÇÃO SOBRE PREÇO E VALOR: UM TESTE EXPERIMENTAL
}

Por:

\section{Daniela Abrantes Serpa \\ Marcos Gonçalves Avila}

RAE-eletrônica, v. 3, n. 2, Art. 13, jul./dez. 2004

http://www.rae.com.br/eletronica/index.cfm?FuseAction=Artigo\&ID=1353\&Secao=MERCADO\&Vol ume $=3 \&$ Numero $=2 \& A n o=2004$

CCopyright, 2004, RAE-eletrônica. Todos os direitos, inclusive de tradução, são reservados. É permitido citar parte de artigos sem autorização prévia desde que seja identificada a fonte. A reprodução total de artigos é proibida. $\mathrm{O}_{s}$ artigos só devem ser usados para uso pessoal e nãocomercial. Em caso de dúvidas, consulte a redação: redacao@ rae.com.br.

A RAE-eletrônica é a revista on-line da FGV-EAESP, totalmente aberta e criada com o objetivo de agilizar a veiculação de trabalhos inéditos. Lançada em janeiro de 2002, com perfil acadêmico, é dedicada a professores, pesquisadores e estudantes. Para mais informações consulte o site www.rae.com.br/eletronica.

RAE-eletrônica

ISSN 1676-5648

(C2004 Fundação Getulio Vargas - Escola de Administração de Empresas de São Paulo.

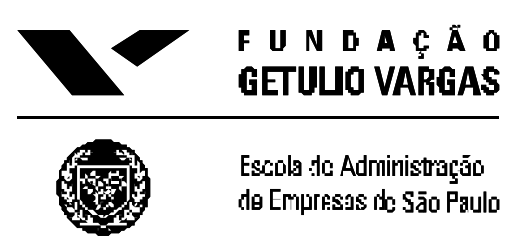




\title{
PERCEPÇÃO SOBRE PREÇO E VALOR: UM TESTE EXPERIMENTAL
}

\section{RESUMO}

Utilizando como fundamentação teórica a Teoria das Perspectivas, de Kahneman e Tversky, este estudo discutiu e testou, em um experimento, o conceito, e determinantes, do preço de referência em decisões de compras. O preço de referência foi definido como aquele que o comprador adota como base para avaliar o preço efetivamente cobrado pelo produto. $\mathrm{O}$ experimento avaliou ainda o poder da variável experiência em marketing em mediar a influência dos fatores que determinam esse preço. Os resultados confirmam evidências de outros estudos e indicam que a maneira de apresentar a decisão influencia a percepção do comprador sobre o preço de referência. A variável experiência gerencial na área de marketing teve impacto parcial na redução da influência dos fatores estudados sobre a percepção de preço por parte dos participantes do experimento.

\begin{abstract}
This study, using Kahneman and Tversky's Prospect Theory as the theoretical reference, discussed and tested, in an experiment, the concept, and determinants, of the reference price in buying decisions. The reference price was defined as the price that the buyer adopts as a basis to evaluate the price effectively charged for the product. The experiment also evaluated managerial experience in marketing as a variable capable of reducing the influence of those determinants. The results are in line with evidences from other studies and indicate that the way the decision is presented influences the buyer's perception over the reference price. The variable managerial experience in marketing had a partial influence in reducing the impact of the factors investigated over the subjects' perception of prices.
\end{abstract}

\section{PALAVRAS-CHAVE}

Comportamento do consumidor, preço de referência, percepção de preço, efeito framing.

\section{KEY WORDS}

Consumer behavior, reference price, price perception, framing effects. 


\section{INTRODUÇÃO}

A escolha de Daniel Kahneman para receber, ao lado de Vernon Smith, o Prêmio Nobel de Economia de 2002 atesta a importância de uma linha de pesquisa que, ao longo dos últimos 30 anos, vem coletando evidências de que as decisões que toma mos violam, de forma sistemática, alguns princípios básicos de consistência. Uma dessas violações é a de que respondemos diferentemente a um mesmo problema decisório se forem feitas mudanças na forma como este problema é apresentado. Kahneman e seu colaborador, Amos Tversky (falecido em 1996), chamaram esse fenômeno de efeito framing e articularam a Teoria das Perspectivas (Kahneman e Tversky, 1979 e Tversky e Kahneman, 1981) para explicá-lo.

$\mathrm{Na}$ área específica de Comportamento do Consumidor, apesar das evidências do efeito framing em decisões de compra serem extensas e robustas (ver, por exemplo, Smith e Nagle, 1995 e Simonson, 1993), elas foram obtidas em estudos desenvolvidos principalmente nos Estados Unidos. Pesquisas com o consumidor brasileiro são limitadas e com resultados pouco conclusivos (Avila e Costa, 1996). Uma primeira questão de interesse deste trabalho se refere, portanto, à manifestação do efeito framing em decisões de compra do consumidor brasileiro. Especificamente, buscamos avaliar se dferentes formas de apresentar informações de preço teriam impacto na decisão de compra.

Uma outra questão que se coloca, a medida em que o efeito framing se manifeste, se refere à existência de fatores que possam reduzir as inconsistências no processo decisório. $\mathrm{O}$ efeito framing resulta de um processo automático, intuitivo, de tomada de decisão e é considerado de difícil eliminação (Tversky e Kahneman, 1984, Hastie e Dawes, 2001). Como Dawes (1988) sugere, entretanto, "se nós não pudéssemos escolher diferentemente, com base em reflexões, haveria pouco sentido em se estudar tomada de decisão" (p. 45). Nesse sentido, e seguindo sugestões da literatura em psicologia da decisão (Fischof, 1982), este estudo procurou também avaliar se experiência e conhecimento especializado no contexto em que a decisão ocorre pode reduzir o efeito framing. Experiência gerencial em marketing foi usada como a definição operacional da variável experiência e conhecimento especializado em decisões de compra e comparamos o desempenho de gerentes de marketing com gerentes de outras áreas (sendo todos os profissionais com pelo menos dois anos de experiência gerencial).

Nas seções que se seguem apresentamos a fundamentação teórica do trabalho e um detalhamento das hipóteses e do método de pesquisa, com as devidas justificativas e limitações referentes as variáveis estudadas e aos procedimentos de pesquisa adotados. Um sumário dos resultados e uma discussão sobre algumas implicações desses resultados concluem então o trabalho.

\section{REFERENCIAL TEÓRICO}

\section{A Teoria das Perspectivas}

As pesquisas de Herbert Simon, Prêmio Nobel de Economia de 1978, constituem um importante ponto de referência no estado atual do conhecimento na área de julgamento e tomada de decisão. Simon (1957) contrastou os métodos considerados racionais, do ponto de vista da teoria clássica microeconômica de tomada de decisão, com as evidências de como as pessoas realmente decidem, e 
indicou haver um hiato entre o que se faz e o que se deveria fazer. $\mathrm{O}$ motivo desse hiato estaria associado a questões cognitivas: "A capacidade humana para formular e solucionar problemas complexos é muito pequena comparada à capacidade que uma solução, dentro dos padrões de comportamento objetivamente racional, requer" (Simon, 1957, p.31). O conceito de racionalidade está associado à obediência, por parte de quem decide, a um conjunto de axiomas. O axioma da invariância (Thaler, 1999) é um deles e determina que a escolha entre opções deve ser independente da maneira como elas são apresentadas.

A Teoria das Perspectivas (Kahneman e Tversky, 1979 e 1984 e Tversky e Kahneman, 1981) segue a tradição das pesquisas de Simon e foi desenvolvida a partir de um conjunto de experimentos que revelaram violações sistemáticas nos axiomas de comportamento racional. A violação ao axioma da invariância é ilustrada a seguir. Kahneman e Tversky (1979) solicitaram aos participantes de uma pesquisa que considerassem as seguintes decisões:

\section{Decisão 1: $\quad$ Opção A: Ganhar \$500 com certeza}

Opção B: $50 \%$ de chances de ganhar $\$ 1.000$

Decisão 2: $\quad$ Você recebe $\$ 1.000$ e

\section{Opção A: perde $\$ 500$ com certeza}

Opção B: $50 \%$ de chances de perder $\$ 1.000$

Não há diferença entre as decisões 1 e 2, sob a perspectiva racional. Em ambas, a opção A significa ficar com $\$ 500$ e a opção B significa $50 \%$ de dhances de ficar com $\$ 1.000$. A maneira como cada decisão foi descrita, entretanto, difere: a decisão 1 induz a posição financeira atual como o ponto de referência para descrever os resultados; já a decisão 2 usa como ponto de referência a posição financeira atual mais \$1000. No experimento, a maioria (72\%) dos respondentes preferiu a opção A quando apresentada à decisão 1, e a maioria (78\%) preferiu B quando apresentada à decisão 2.

Tversky e Kahneman (1981), conforme já mencionado, cunharam a expressão "efito framing" para descrever a possibilidade de reverter preferências em decisões, de forma sistemática, por meio de alterações na forma de apresentar o problema. Para explicar esse efeito, a Teoria das Perspectivas distingue duas fases no processo decisório individual. A primeira fase é de edição e estruturação da decisão (Kahneman e Tversky, 1979), e tem como objetivo organizar e reformular as opções, de maneira a simplificar o problema. Resulta dessa etapa uma percepção do tomador de decisão sobre os elementos essenciais da decisão - as alternativas, os resultados da adoção de cada alternativa e as probabilidades associadas à ocorrência desses resultados. A segunda fase do processo decisório envolve a avaliação das alternativas e a escolha final. Do interesse deste estudo estão os conceitos da teoria relacionados à edição da decisão e a discussão que se segue estará focada nesse processo.

Para Kahneman e Tversky $(1979,1981)$ o processo de edição leva as pessoas a perceberem os resultados da decisão não como alterações no estado final de riqueza ou bem-estar, mas como ganhos ou perdas em relação a um ponto de referência, o qual a pessoa assume para a situação de decisão. O já mencionado experimento de Kahneman e Tversky (1979) ilustra o conceito de ponto de referência. Os autores justificam sua importância: "nosso aparato de percepção está associado a avaliações de mudanças ou diferenças e não a avaliações de valores absolutos. Assim, um objeto a uma dada temperatura pode ser percebido como frio ou quente dependendo da temperatura a que a pessoa está adaptada. O mesmo princípio se aplica a atributos não sensoriais, como riqueza, prestígio e saúde. $\mathrm{O}$ 
mesmo nível de riqueza, por exemplo, pode implicar em pobreza para uma pessoa e grande riqueza para outra pessoa - dependendo da riqueza atual de cada um" (Kahneman e Tversky, 1979, p. 277).

De acordo com a Teoria das Perspectivas, os ganhos ou perdas em relação ao ponto de referência são avaliados não pelo seu valor objetivo, mas por um valor subjetivo e pessoal. Essa noção de valor corresponde à noção de utilidade na teoria microeconômica clássica, e representa uma medida de satisfação, que pode ser associada a cada resultado. Segundo Kahneman e Tversky (1979), a relação entre o resultado da decisão (o ganho ou a perda) e o valor (ou utilidade) atribuído ao resultado é tal que as pessoas são mais sensitivas a diferenças entre resultados quando estes estão perto do ponto de referência. Em outras palavras, a diferença, em valores subjetivos, entre um ganho de \$10 para \$20 é percebida como maior do que a diferença entre um ganho de $\$ 110$ para $\$ 120$. Finalmente, a Teoria das Perspectivas sugere que a intensidade da sensação associada à perda de um determinado montante é maior que a intensidade associada a um ganho do mesmo montante.

A Figura 1 sumariza graficamente as propostas da Teoria das Perspectivas associadas à noção de ponto de referência. A função mostra, no eixo horizontal, os resultados da decisão como desvios do ponto de referência e associa, no eixo vertical, um valor subjetivo a cada resultado. Seu formato em $\mathrm{S}$ faz com que seja côncava para ganhos, de forma que cada unidade extra que seja ganha adiciona menos valor (utilidade) do que a precedente. No campo das perdas, a função é convexa, de forma que cada unidade perdida causa uma mudança menor no valor (utilidade) do que a precedente. A curva é mais íngreme do lado de perdas, de maneira a incorporar a noção de que somos mais sensíveis a perdas do que a ganhos de mesmo valor.

Figura 1 - Função valor.

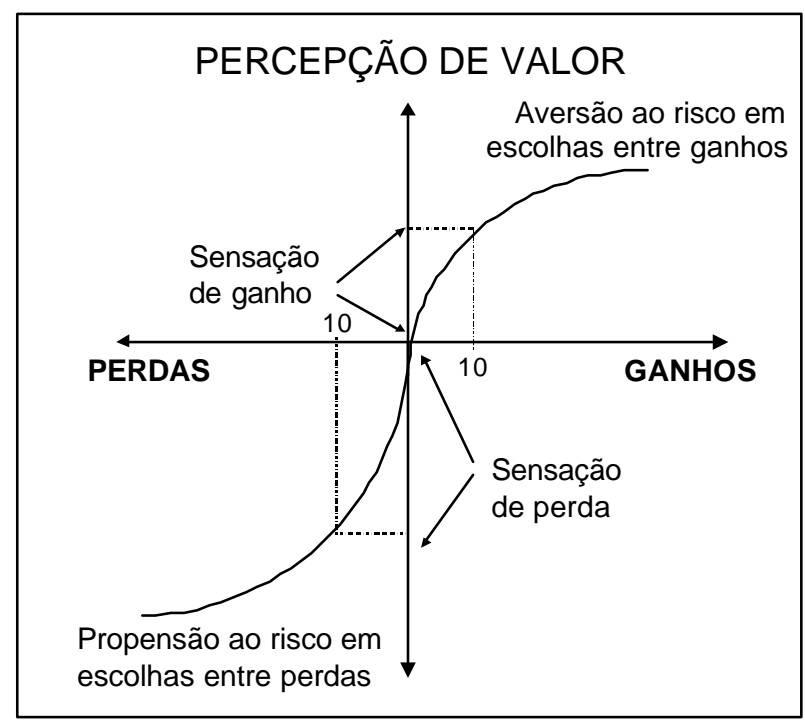

Fonte: Tversky e Kahneman (1984)

A curva em $\mathrm{S}$ da função-valor equivale à denominada lei Weber-Fechner, para a qual o montante que um estímulo precisa ser aumentado (ou diminuído) para que a diferença seja notada é proporcional ao valor do estímulo de referência (Dawes, 1988). Por exemplo, em relação a peso, a proporção que precisa ser aumentada de determinado valor para que a diferença seja percebida é avaliada como devendo ser de, pelo menos, 2,8\% (Dawes, 1988). A Teoria das Perspectivas sugere, portanto, conforme assinalou Russo e Schoemaker (1989, p. 28), que "as pessoas tendem a pensar sobre economias em termos percentuais e não em dólares absolutos", isto é, informações de ganhos ou perdas são processadas em termos relativos. Um 
experimento de Kahneman e Tversky (1984) ilustra esse ponto. Os autores contrastaram dois cenários de promoção de preços:

A: Imagine que você está preste a comprar uma jaqueta por $\$ 125$. O vendedor lhe informa que a jaqueta que você deseja comprar está em promoção por \$120 em uma filial da loja que fica a 20 minutos de carro. Você faria a viagem até a outra loja?

B: Imagine que você está preste a comprar uma calculadora por $\$ 15$. O vendedor lhe informa que a calculadora que você deseja comprar está em promoção por \$10 em uma filial da bja que fica a 20 minutos de carro. Você faria a viagem até a outra loja?

Um comportamento decisório racional em relação a esse problema desconsideraria a informação do preço do produto; o fato relevante é o de que em ambos os casos o custo a ser incorrido para usufruir o benefício do desconto é o mesmo. Os resultados do experimento mostraram, entretanto, que $68 \%$ dos respondentes estavam dispostos a viajar até a outra loja para economizar $\$ 5$ na compra da calculadora, mas somente $29 \%$ viajariam para economizar o mesmo valor na compra da jaqueta.

\section{Teoria das perspectivas e definição de preços: o conceito de preço de referência}

O conceito de preço de referência, bem como sua associação com a Teoria das Perspectivas, foi inicialmente proposto por Thaler (1980 e 1985), que o definiu como sendo aquele usado pelo consumidor como base para julgar o preço efetivamente cobrado pelo objeto da compra. A noção de justiça (fairness na expressão usada pelo autor) determina a fixação do preço de referência. Em outras palavras, o preço de referência é o preço que o comprador considera razoável, justo. Os experimentos de Kahneman, Knetsch e Thaler (1990) testaram essa noção de justiça na formação de preços de referência. Um dos experimentos apresentou aos participantes do estud o dois cenários:

A: Uma empresa desenvolveu um modelo popular de automóvel e os consumidores agora têm que esperar dois meses para a entrega. Uma concessionária tem vendido o carro ao preço de tabela. Agora esta concessionária está vendendo este carro ao preço por \$200 acima do preço de tabela.

B: Uma empresa desenvolveu um modelo popular de automóvel e os consumidores agora têm que esperar dois meses para a entrega. Uma concessionária tem vendido o carro com um desconto de \$200 em relação ao preço de tabela. Agora esta concessionária está vendendo este carro ao preço de tabela.

Sob a perspectiva racional, segundo o princípio da invariância, os cenários são idênticos, isto é, a diferença de preço em ambos é de \$200. Logo, as respostas deveriam seguir o mesmo padrão, independente do cenário. Entretanto, do grupo que analisou o cenário A, $71 \%$ considerou a situação injusta, ao passo que do grupo que analisou o cenário B, $58 \%$ manifestou essa opinião. Aparentemente, o preço de tabela foi adotado como o de referência e, portanto, no cenário $\mathrm{A}$, o aumento de $\$ 200$ foi considerado abusivo. Bazerman (1998, p. 80) comenta que "os consumidores parecem dar status especial ao preço de tabela do produtor, mesmo quando não esperam pagar aquele montante".

Thaler (1985) argumenta que o preço de referência, isto é, o preço percebido como justo, depende em grande escala da percepção que o consumidor tem sobre o custo do produto para o vendedor. O experimento descrito a seguir testou essa proposta. Thaler (1985) submeteu aos participantes dois contextos de compra - expressos a seguir entre parênteses e colchetes - e solicitou um posicionamento quanto ao preço a pagar por um produto: 
Você está em uma praia num dia quente. Tudo o que você tem para beber é água gelada. Durante a última hora, você esteve pensando o quanto gostaria de beber uma garrafa de sua marca favorita de cerveja. Um companheiro se levanta para dar um telefonema e se oferece para trazer a cerveja do único lugar nas proximidades onde se vende cerveja: [um armazém pequeno e decadente] (um hotel de luxo). Ele diz que a cerveja pode custar caro e pergunta quanto você estaria disposto a pagar por ela. Ele diz que comprará a cerveja se ela custar tanto quanto ou menos do que o preço que você indicar. Mas se custar mais que este último, ele não a comprará. Você confia em seu amigo e não há possibilidade de se barganhar com o [dono do armazém] (barman do hotel). Que preço você estipula para ele?

O produto é o mesmo nos dois cenários e o luxo do hotel não é relevante, na me dida em que a pessoa estará consumindo a cerveja na praia em ambas as situações. No entanto, a média dos valores de preço indicados nas versões "hotel de luxo" e "armazém" foi de $\$ 2,65$ e $\$ 1,50$, respectivamente. Segundo Thaler (1985), esse padrão de respostas indica que, além do prazer, da satisfação (utilidade) que terá em relação ao produto que está sendo adquirido, o consumidor avalia os méritos do processo de compra em si. Este autor chamou de utilidade transacional a medida de satisfação associada à transação de compra. No que se refere a preço, a utilidade transacional se dá pela diferença entre o preço efetivamente cobrado e o preço de referência adotado na transação. Se este último for maior que o primeiro, então a satisfação do consumidor em relação à transação de compra será positiva.

A proposta de aplicação da noção de preço de referência no campo de marketing tem sido ampla: se a percepção de preço de referência que o comprador adotar pode ser influenciada pela forma como a decisão de compra é apresentada (o efeitoframing), então o gerenciamento de percepções sobre preços se torna possível e relevante.

Nagle (2002) registra a importância do gerenciamento da percepção de preços e sugere uma relação de fatores que definem essa percepção: "É óbvio que os compradores também se negam a pagar preços que consideram 'abusivos' (aspas no original). Com certeza, não há critérios rigorosos para determinar quão justo é um preço, mas um bom ponto de partida é analisar certos fatores que influem na percepção dos consumidores: o comportamento histórico dos preços, a comparação com produtos similares e as 'necessidades básicas' (aspas no original) - as pessoas não gostam de pagar preços altos por produtos que cobrem necessidades básicas, como os de cuidado com a saúde" (p.68).

Smith e Nagle (1995) e Nagle e Holden (1995 e 2002) expandem esta discussão e sugerem que três categorias de informação influenciam a formação do preço de referência pelo consumidor: o preço corrente a que ele está exposto, os preços passados lembrados por ele, e o contexto de compra no qual o preço é oferecido. A discussão a seguir detalha as considerações sobre cada uma dessas categorias.

Em relação aos preços correntes aos quais o comprador está exposto, os autores concordam que os compradores utilizam os primeiros preços com os quais interagem para desenvolver uma referência inicial, o qual os ajuda a julgar os outros preços. Smith e Nagle (1995) apresentaram a um grupo de pessoas preços de canetas em ordem descendente e a outro grupo, estes mesmos preços em ordem ascendente. Depois foi pedido aos participantes que respondessem que preço esperavam pagar por uma caneta, que preço considerariam como justo e quanto efetivamente pagariam no máximo. Os participantes do primeiro grupo, que avaliaram preços em ordem descendente, indicaram preços esperados mais altos, preços justos mais altos e mostraram-se dispostos a pagar mais por uma caneta do que os participantes do segundo grupo. Os autores justificam este resultado através da mudança na ordem em que os preços foram apresentados para cada grupo pesquisado. 
Ainda em relação aos preços correntes, Smith e Nagle (1995) afirmam que acrescentar um produto mais caro a uma linha de produtos eleva o preço de referência dos consumidores, fazendo com que os preços dos demais produtos da linha sejam percebidos como mais baratos. Um estudo de Simonson e Tversky (1992) testou este efeito. A um grupo de pessoas foi pedido que escolhessem um, dentre alguns modelos de fornos de microondas. Metade das pessoas de veria escolher entre dois modelos e a outra metade tinha três opções para escolha. Os resultados encontrados foram os seguintes:

\begin{tabular}{|l|c|c|}
\hline & \multicolumn{2}{|c|}{ ESCOLHA (\%) } \\
\hline Modelo de Microondas & $\begin{array}{c}\text { Grupo 1 } \\
\mathrm{n}=60\end{array}$ & $\begin{array}{c}\text { Grupo 2 } \\
\mathrm{n}=60\end{array}$ \\
\hline $\begin{array}{l}\text { Panasonic II (1.1 pés cúbicos; preço regular \$199,99; preço de } \\
\text { venda com 10\% de desconto) }\end{array}$ & - & 13 \\
$\begin{array}{l}\text { Panasonic I (0.8 pés cúbicos; preço regular \$179,99; preço de } \\
\text { venda com 35\% de desconto) }\end{array}$ & 43 & 60 \\
\hline $\begin{array}{l}\text { Emerson (0.5 pés cúbicos; preço regular \$109,99; preço de venda } \\
\text { com 35\% de desconto) }\end{array}$ & 57 & 27 \\
\hline
\end{tabular}

No tocante à segunda categoria de informação que influencia a formação do preço de referência, preços passados que o comprador traz na memória, é comum encontrarmos materiais publicitários em que os anunciantes sugerem aos consumidores qual o preço que eles pagaram por determinado produto quando o compraram no passado, às vezes utilizando a conhecida técnica de expor preços sob a forma de "De... Por...". A credibilidade deste tipo de referência, no entanto, depende em grande parte da discrepância entre os dois preços (Urbany et ali, 1988).

Finalmente, em relação à terceira categoria de informação, contexto de compra como referência, Nagle e Holden (1995) assinalam, em concordância com a proposta de Thaler (1985), que os preços de referência do comprador são influenciados não só pelo que ele estaria disposto a pagar no contexto de compra, mas também pelo que considera que seja justo do vendedor cobrar. Neste sentido, uma maneira de o comprador inferir se há ou não justiça é fazer uma avaliação sobre o custo do produto para o vendedor, conforme ilustrou o já mencionado experimento sobre a compra de uma cerveja em diferentes locais.

\section{HIPÓTESES E METODOLOGIA DE PESQUISA}

\section{Hipóteses de Pesquisa e Método}

Duas perguntas norteiam as hipóteses a serem testadas neste estudo: respondemos diferentemente a um mesmo problema decisório se o problema é apresentado de uma maneira diferenciada? E até que ponto experiência e conhecimento especializados na área de decisões de compra podem reduzir o efeito framing? Profissionais de marketing trabalham diretamente com a estruturação de aspectos envolvidos nas situações de compra, sendo deles a responsabilidade em definir estratégias referentes ao composto de marketing - produto, preço, distribuição e comunicação (Kotler, 1996). Essa exposição continuada, repetitiva, a situações decisórias envolvendo variáveis de marketing cria uma oportunidade acentuada de aprendizado. Logo, se o conhecimento especializado na área em que a decisão ocorre tem impacto 
no efeito framing, profissionais de marketing devem mostrar menor suscetibilidade a influenciar-se por mudanças na maneira como a situação de decisão é apresentada.

Reconhecemos as limitações estatísticas dessa definição operacional para a variável referente à experiência ou educação substantiva em área de especialização associada ao comportamento do consumidor e formulação de preços. A adoção, entretanto, de critérios mais rígidos de definição para essa variável (por exemplo, pelo menos cinco anos de experiência específica na área de estratégia de preço) foi percebida como inviável. Por isso, e dada a natureza pioneira da investigação, já que desconhecemos outros estudos que tenham tentado avaliar a relação entre o efeito framing e a experiência em marketing, decidimos incluir a variável no estudo da forma como foi definida.

A metodologia de pesquisa seguiu o padrão adotado nas investigações dos principais pesquisadores do tema: experimento, com questionários contendo perguntas curtas em situações hipotéticas, em que se apela para a intuição dos respondentes. Tha ler (1999) articula os princípios metodológicos associados a essa linha de investigação e argumenta que questões hipotéticas parecem funcionar bem quando os participantes têm acesso a suas intuições e não têm qualquer incentivo em mentir.

O experimento contou com duas variáveis independentes: a maneira de apresentar o problema decisório e a existência ou não de experiência gerencial em marketing. Cada variável teve dois níveis e o experimento foi, portanto, um delineamento fatorial $2 \times 2$. A variável dependente do estudo foi a medida de percepção relativa a preço. A amostra total era composta de 120 participantes, distribuídos aleatoriamente pelos quatro subgrupos da pesquisa, como mostra a tabela a seguir:

\begin{tabular}{|l|c|c|}
\hline & $\begin{array}{c}\text { QUESTIONÁRIO - } \\
\text { VERSÃO A }\end{array}$ & $\begin{array}{c}\text { QUESTIONÁRIO - } \\
\text { VERSÃO B }\end{array}$ \\
\hline Gerentes com experiência em marketing & 30 & 30 \\
\hline $\begin{array}{l}\text { Gerentes com experiência em outras áreas da } \\
\text { administração }\end{array}$ & 30 & 30 \\
\hline
\end{tabular}

O procedimento estatístico utilizado foi o ANOVA, complementado com o cálculo da estatística t para verificação de diferença significativa entre médias. Sendo o tamanho de amostra em cada célula de 30 participantes, vale enfatizar algumas considerações apontadas por Hair et al. (1998) sobre pressupostos de amostras para uso de técnicas de análises de variâncias. Estes autores indicam que tamanhos desiguais de amostra nos subgrupos de pesquisa podem influenciar os resultados obtidos e fazer com que sejam necessárias análises adicionais; neste estudo as amostras eram do mesmo tamanho. Por outro lado, amostras de 30 participantes, embora cumpram o mínimo de tamanho necessário para ter suas observações aproximadas da distribuição normal, podem influenciar no poder estatístico das análises de variâncias, fato que vale como ressalva para limitação deste estudo. A fim de minimizar esta limitação, o teste não-paramétrico Wilcoxon Signed Ranks também foi realizado, e os resultados encontrados apontam para a confirmação do que foi obtido através do ANOVA.

Experimentos fatoriais podem medir o efeito separado de cada variável independente sobre a variável dependente (o efeito principal) e o efeito conjunto das variáveis independentes sobre a variável dependente (o efeito interação). A interação acontece quando os efeitos de uma variável independente são diferentes, em níveis distintos, da outra variável independente (Kerlinger, 1980). O interesse desta pesquisa concentra-se no efeito principal da variável "maneira de apresentar o problema" (efeito framing) e no efeito interação entre as duas variáveis independentes, isto é, na avaliação se o impacto do efeito framing na variável dependente era influenciado pelo tipo de experiência gerencial dos respondentes. 
O questionário respondido pelos participantes da pesquisa continha quatro perguntas, cada qual com duas versões. A primeira pergunta replica o estudo de Thaler (1985). A manipulação da variável "maneira de apresentar o problema" está indicada nos parênteses e colchetes. A variável dependente foi o preço máximo estipulado para a compra.

Você está deitado em uma praia num dia quente. Tudo o que você tem para beber é água. Durante a última hora, você esteve pensando o quanto gostaria de beber uma lata de seu refrigerante favorito. Um amigo se levanta para dar um telefonema e se oferece para trazer o refrigerante do único lugar nas proximidades que vende o produto - [um hotel de luxo] (um pequeno armazém). Ele diz que há a possibilidade de o refrigerante vir a custar caro e pergunta o quanto você está disposto a pagar por ele. Ele diz que comprará o refrigerante se ele custar igual ou menos que o preço que você indicar. Se custar mais, ele não compra. Assuma que não há possibilidade de se barganhar com o [atendente do bar do hotel] (atendente do armazém). Que preço você estipula?

Sob a perspectiva racional, a diferença no contexto de compra não deveria influenciar a fixação do preço máximo, pois o produto é o mesmo em ambas as situações e a pessoa não irá desfrutar do ambiente do hotel de luxo. O conceito de utilidade transacional sugere, entretanto, que o consumidor irá adotar preços de referência diferentes para os dois contextos e, portanto, irá definir um preço máximo também diferente. Logo, as hipóteses, nas formas nula e alternativa, são:

H01: O preço máximo médio a ser estipulado para o refrigerante no armazém e no hotel de luxo serão os mesmos.

H11: O preço máximo médio para o refrigerante será maior no caso de a compra se realizar no hotel de luxo (ocorrência do efeito framing).

H02: Não há relação entre o preço máximo médio solicitado e a experiência gerencial em marketing.

H12: O efeito framing só se manifestará no grupo sem experiência gerencial em marketing.

O problema recém-descrito já havia sido aplicado no Brasil (Avila e Costa, 1996), com a hipótese do impacto do contexto da compra na definição do preço máximo não tendo sido confirmada. À época, entretanto, os resquícios da inflação em que viveu o Brasil por tantos anos eram fortes e as noções de preço e valor encontravamse sob questionamento. Considerourse, então, que o controle do experimento sobre a influência dessa cultura inflacionária pode ter sido inadequado.

A segunda pergunta do questionário replica o experimento de Kahneman e Tversky (1984) e testa a noção de que respondemos à diferença de preços não em termos de uma avaliação desta diferença em reais, mas em termos percentuais. A variável dependente neste estudo foi o desconto mínimo exigido para o deslocamento até a outra loja.

Imagine que você está numa loja prestes a comprar [uma calculadora] (uma televisão) por [R \$ 50] ( $\mathrm{R} \$ 500)$. O vendedor lhe informa que a mesma [calculadora] (televisão) está em promoção em uma outra filial da loja, localizada a uma distância de 10 quarteirões - assuma que você terá que se deslocar a pé. Qual é o desconto mínimo - em reais - para a [calculadora] (televisão) que a outra loja teria que lhe dar para valer a pena se deslocar até lá?

Sob a perspectiva racional, a inclusão de diferentes preços de referência não deveria influenciar a fixação do desconto mínimo, dado que o esforço requerido é o mesmo em ambas as situações. A 
proposta de que raciocinamos em termos percentuais, pelo formato da função-valor, leva a prever um resultado diferente. Logo, temos como hipóteses nulas e alternativas:

H03: O desconto mínimo médio a ser estipulado será o mesmo, independente do produto em promoção.

H13: O desconto mínimo médio a ser estipulado para a televisão será maior do que o desconto mínimo médio a ser estipulado para a calculadora (ocorrência do efeito framing).

H04: Não há relação entre experiência gerencial na área de marketing e o desconto mínimo médio a ser estipulado.

H14: O efeito framing só se manifestará no grupo sem experiência gerencial em marketing.

A terceira pergunta do questionário replica o estudo de Kahneman e Tversky (1984) e testa o impacto da noção de justiça na formação da percepção sobre preço de referência. A variável dependente do estudo foi o julgamento do preço final de compra, isto é, se este era justo ou não.

Você deseja comprar um determinado carro, cuja procura tornourse tão grande que os consumidores agora têm que esperar 2 meses para a entrega. Antes do aumento na procura, as concessionárias vendiam este carro [pelo preço de tabela] (com desconto de $\mathrm{R} \$ 2.000 \mathrm{em}$ relação ao preço de tabela). Agora as concessionárias estão cobrando [R $\$ 2.000$ acima do preço de tabela] (o preço de tabela). Você cons idera esta situação:

\section{Resposta: （ ) ACEITÁVEL （ ) INJUSTA}

A diferença de preço do carro entre os dois momentos é de $\$ 200$, em ambos os cenários, que, portanto, se equivalem. Conforme discutido, entretanto, se o preço de tabela atuar como o preço de referência para o produto, os cenários serão percebidos de forma distinta. Logo as hipóteses nulas e alternativas são:

H05: A proporção das pessoas que julgam como injusta a mudança de preço será a mesma em ambas as formulações do problema.

H15: A proporção das pessoas que julgam como injusta a mudança de preço será maior na situação em que o produto está sendo vendido acima do preço de tabela (ocorrência do efeito framing).

H05: Não há relação entre experiência gerencial na área de marketing e a avaliação sobre justiça.

H15: O efeito framing só se manifestará no grupo sem experiência gerencial em marketing.

A última pergunta do questionário replica o estudo de Simonson e Tversy (1992) e testa a proposta de que o acréscimo de um produto mais caro a uma linha de produtos eleva o preço de referência fazendo com que os preços dos demais produtos pareçam mais baratos.

A variável dependente foi a opção de compra em relação ao eletrodoméstico. Cada versão do problema foi colocada como segue:

Versão A: Suponha que você está precisando comprar um forno de microondas para sua casa e tem que escolher entre estes dois modelos: 


\section{MERCADOLOGIA - PERCEPÇÃO SOBRE PREÇO E VALOR: UM TESTE EXPERIMENTAL \\ Daniela Abrantes Serpa - Marcos Gonçalves Avila \\ BRASTEMP I \\ Tamanho: 27 litros}

Preço: $\mathrm{R} \$ 399,00$ com desconto de 35\% na promoção

SHARP

Tamanho: 19 litros

Preço: $\mathrm{R} \$ 249,00$ com desconto de $35 \%$ na promoção

Qual modelo você compraria?

Versão B: Suponha que você está precisando comprar um forno de microondas para sua casa e tem que escolher entre estes três modelos:

BRASTEMP II Tamanho: 38 litros

Preço: $\mathrm{R} \$ 539,00$ com desconto de $10 \%$ na promoção

BRASTEMP I Tamanho: 27 litros

Preço: $\mathrm{R}$ \$ 399,00 com desconto de 35\% na promoção

SHARP Tamanho: 19 litros

Preço: $\mathrm{R}$ \$ 249,00 com desconto de 35\% na promoção

Qual modelo você compraria?

O produto premium acrescido à linha de produtos na versão $\mathrm{B}$ manteve a marca do produto mais caro na versão A do questionário (marca Brastemp), seguindo a estrutura do experimento de Simonson e Tversky (1993). Testes-pilotos foram realizados trocando-se as marcas dos produtos (colocando-se Brastemp, Sharp I, Sharp II) e resultados similares ao deste estudo foram encontrados. Embora o produto premium acrescido à linha pudesse, em princípio, ser de uma marca diferente, acreditamos que a manutenção da marca com a diferença de preços é preferível. O objetivo da inclusão do produto premium na versão B é o de gerar a percepção de que o novo produto é de maior qualidade do que os demais, e, em consequiência, deslocar para cima o preço de referência do consumidor. A manutenção da marca, com a diferença focada no preço, cumpre esse papel. A adoção de uma nova marca teria que ser precedida de testes-pilotos que atestassem que o produto premium não era percebido como de qualidade inferior ao da marca Brastemp (mesmo com preço mais alto).

As hipóteses relativas a esse problema foram:

H07: A proporção das pessoas que escolherão o produto Brastemp I será a mesma em ambas as versões do problema.

H17: A proporção das pessoas que escolherão o produto Brastemp I será maior na versão em que um terceiro produto mais caro é inserido na lista (o efeito framing). 
H08: Não há relação entre experiência gerencial na área de marketing e a preferência pelo produto Brastemp I.

H18: O efeito framing só se manifestará no grupo sem experiência gerencial na área de marketing.

\section{Procedimentos experimentais}

Kerlinger (1980) indica que "um experimento requer, no mínimo, dois grupos experimentais. Esses grupos podem ser designados como 'experimental' e de 'controle', ou A1 e A2, ou de outra maneira conveniente" (p. 141, aspas no original). Quatro grupos experimentais -cada um com 30 participantes participaram deste estudo, somando um total de 120 pessoas, conforme ilustrado anteriormente. Todos os participantes acumulavam experiência gerencial mínima de dois anos (metade com experiência na área de marketing e metade com experiência gerencial em outras áreas de administração). Os participantes, com idade entre 26 e 35 anos, eram alunos de cursos de especialização (MBA) em administração e marketing de uma instituição de ensino do Rio de Janeiro. Por designação aleatória, metade dos participantes recebeu o questionário com uma versão (frame) da pergunta e metade com a outra versão.

Uma limitação do procedimento de pesquisa se refere ao controle sobre as variáveis do experimento. Como indica Kerlinger (1980), "a força básica da pesquisa experimental está no controle relativamente alto da situação experimental e, conseqüentemente, das possíveis variáveis independentes que possam afetar as variáveis dependentes" (p. 127). As ameaças ao controle são classificadas em questões de validade interna e de validade externa (Nachmias e Nachmias, 1987). A validade interna é dada pelo controle sobre a possibilidade de que outros fatores, que não as variáveis independentes, possam estar influenciando o comportamento da variável dependente. A maneira usual de assegurar a validade interna se dá através da designação aleatória dos participantes da pesquisa aos grupos experimentais. Este procedimento foi adotado no caso da variável independente "maneira de apresentar a decisão", mas não foi adotado em relação à variável "experiência gerencial", pela própria característica desta variável. Uma forma alternativa de se buscar a validade interna é emparelhando os participantes nos diversos grupos experimentais com o objetivo de garantir características semelhantes em todas as variáveis que não a variável independente (por exemplo, mesma idade, mesmo tempo de experiência, mesmo sexo. etc.). Este procedimento tem duas limitações. Em primeiro lugar, é difícil de se estabelecer quais as variáveis que deveriam ser consideradas nesse processo de emparelhamento. Em segundo lugar, esse procedimento, novamente, inviabilizaria a obtenção de uma amostra significativa para o experimento.

A discussão sobre a validade externa da pesquisa se refere à capacidade de generalização dos resultados, tanto para populações maiores do que a amostra que participou do estudo quanto para situações reais de decisão. Em relação a essa questão, Kerlinger (1980) comenta: "Em geral os resultados de experimentos de laboratório não podem ser generalizados além do laboratório. Só porque certos resultados foram obtidos em laboratórios não se pode dizer que resultado idêntico ou semelhante ocorrerá fora do laboratório - embora possa, e muito bem. Deve-se mostrar, através de pesquisas posteriores, que os resultados se aplicam no campo" (p.129). 


\section{RESULTADOS}

A seguir serão apresentados os resultados relativos a cada pergunta do questionário.

Problema 1:

\begin{tabular}{cccr}
\hline & Maneira de apresentar & o problema & \\
Experiência & "Hotel de luxo" & "Pequeno armazém" & Média Geral \\
Com & $\$ 3,43^{*}$ & $\$ 3,22$ & $\$ 3,32$ \\
Sem & $\$ 2,93$ & $\$ 2,18$ & $\$ 2,55$ \\
Média Geral & $\$ 3,18$ & $\$ 2,70$ & \\
\hline * Preço médio máximo. &
\end{tabular}

Tabela ANOVA

\begin{tabular}{|l|c|c|c|c|}
\hline Fonte de variação & $\begin{array}{c}\text { Soma de } \\
\text { quadrados }\end{array}$ & $\begin{array}{c}\text { Graus de } \\
\text { liberdade }\end{array}$ & F & Sig. \\
\hline Framing & 10,806 & 01 & 7,400 & 0,008 \\
\hline Exp. em Mktg & 14,693 & 01 & 10,062 & 0,002 \\
\hline Framing* Exp. em Mktg & 4,405 & 01 & 3,016 & 0,085 \\
\hline Total & 1261,304 & 120 & & \\
\hline
\end{tabular}

A aplicação do procedimento estatístico ANOVA mostrou que a diferença de preços entre os dois contextos de compra foi significativa $(\mathrm{F}=7,40 ; \mathrm{p}=0,01)$, confirmando, portanto, o efeito framing. $\mathrm{O}$ efeito interação entre as duas variáveis independentes também ocorreu $(\mathrm{F}=3,02 ; \mathrm{p}=0,08)$, o que significa que o efeito framing manifestou-se de forma diferenciada no grupo com experiência na área de marketing e no grupo sem esta experiência. A aplicação do teste t para verificar se há diferença entre as médias do grupo com experiência e do grupo sem experiência confirma esse resultado. No grupo dos profissionais de marketing foi observado que não há diferença significativa entre os preços máximos médios estipulados para o refrigerante no hotel de luxo e no armazém, isto é, o efeito framing não se manifestou de maneira estatisticamente significativa $(\mathrm{t}=-0,70 ; \mathrm{p}=0,24)$. De forma inversa, no grupo composto por profissionais que não são da área de marketing, o efeito framing manifestour se, ficando o preço máximo médio estipulado para o hotel de luxo significativamente maior do que aquele estipulado para a versão armazém $(\mathrm{t}=3,11 ; \mathrm{p}=0,00)$. Estes resultados sugerem que a experiência gerencial na área de marketing contribui para que os indivíduos estejam menos sujeitos ao efeitoframing nas tomadas de decisão de compra.

Problema 2:

\begin{tabular}{lccc}
\hline & Maneira de apresentar & o problema & \\
Experiência & Versão "calculadora" & Versão "televisão" & Média Geral \\
Com & $\$ 16,50 *$ & $\$ 31,67$ & $\$ 24,08$ \\
Sem & $\$ 9,50$ & $\$ 59,67$ & $\$ 39,33$ \\
Média Geral & $\$ 13,00$ & $\$ 45,67$ & \\
\hline * Desconto médio mínimo. & &
\end{tabular}


Tabela ANOVA

\begin{tabular}{|l|c|c|c|c|}
\hline Fonte de variação & Soma de quadrados & Graus de liberdade & F & Sig. \\
\hline Framing & 32013,333 & 01 & 106,594 & 0,000 \\
\hline Exp. em Mktg & 3307,500 & 01 & 11,013 & 0,001 \\
\hline Framing* Exp. em Mktg & 9187,500 & 01 & 30,591 & 0,000 \\
\hline Total & 182600,000 & 120 & & \\
\hline
\end{tabular}

A aplicação da ANOVA neste problema confirmou, novamente, o efeito framing $(\mathrm{F}=106,59 ; \mathrm{p}=0,00)$; o desconto mínimo médio requerido para a calculadora foi inferior ao desconto mínimo médio requerido para a televisão. O efeito interação entre as duas variáveis independentes também foi significativo $(\mathrm{F}=30,59 ; \mathrm{p}=0,00)$ e indica que o efeito framing foi mais pronunciado no grupo sem experiência gerencial em marketing. A aplicação do teste t mostra, entretanto, que há difere nça entre a média dos descontos requeridos para calculadora e para televisão tanto no grupo sem experiência gerencial na área de marketing $(\mathrm{t}=-8,62 ; \mathrm{p}=0,00)$, quanto no grupo com experiência $(\mathrm{t}=-6,10 ; \mathrm{p}=0,00)$.

Problema 3:

\begin{tabular}{lcc}
\hline & \multicolumn{2}{c}{ Maneira de apresentar o problema } \\
Experiência & Preço Final: Acima & Preço Final: Tabela \\
Com & $57 \% *$ & $50 \%$ \\
Sem & $80 \%$ & $53 \%$ \\
Total & $68 \%$ & $52 \%$ \\
\hline$* \%$ de escolha da resposta "Injusta" & &
\end{tabular}

*\% de escolha da resposta "Injusta".

Tabela ANOVA

\begin{tabular}{|l|c|c|c|c|}
\hline Fonte de variação & $\begin{array}{c}\text { Soma de } \\
\text { quadrados }\end{array}$ & $\begin{array}{c}\text { Graus de } \\
\text { liberdade }\end{array}$ & F & Sig. \\
\hline Framing & 0,833 & 01 & 3,563 & 0,062 \\
\hline Exp. em Mktg & 0,533 & 01 & 2,280 & 0,134 \\
\hline Framing* Exp. em Mktg & 0,300 & 01 & 1,283 & 0,260 \\
\hline Total & 48,000 & 120 & & \\
\hline
\end{tabular}

O procedimento ANOVA confirmou o efeito framing $(\mathrm{F}=3,56 ; \mathrm{p}=0,06)$; a variação na descrição do problema afetou a percepção de justiça, embora a diferença de preço seja a mesma nos dois cenários. $\mathrm{O}$ efeito interação entre as duas variáveis independentes não foi significativo $(\mathrm{F}=1,28 ; \mathrm{p}=0,260)$. A realização de um teste $t$ de diferença entre proporções, entretanto, seguindo recomendação de Pagano (1986), mostrou que no grupo comexperiência gerencial na área de marketing o percentual de escolha da opção "injusta" não foi estatisticamente diferente nas duas versões do questionário ( $\mathrm{t}=0,73$; $\mathrm{p}=0,46)$. Já no grupo sem experiência de marketing, este percentual de respostas mostrout se distinto nas duas versões $(t=2,93 ; p=0,00)$. Estes resultados sugerem que o efeito framing manifestou-se apenas no grupo sem experiência na área de marketing. Uma vez que o procedimento ANOVA mostrou a não ocorrência do efeito interação, pode estar havendo um problema de poder estatístico para capturar o efeito interação. Uma amostra maior pode ser necessária para corroborar os resultados estatísticos encontrados. 
Problema 4:

\begin{tabular}{lcc}
\hline & \multicolumn{3}{c}{ Maneira de apresentar o problema } \\
Experiência & Versão 2 Opções & Versão 3 Opções \\
Com & $37 \% *$ & $40 \%$ \\
Sem & $43 \%$ & $77 \%$ \\
Total & $40 \%$ & $58 \%$ \\
\hline
\end{tabular}

* \% de escolha do produto Brastemp I vs. outros.

Tabela ANOVA

\begin{tabular}{|l|c|c|c|c|}
\hline Fonte de variação & Soma de quadrados & Graus de liberdade & F & Sig. \\
\hline Framing & 1,008 & 01 & 4,348 & 0,039 \\
\hline Exp. em Mktg & 1,408 & 01 & 6,073 & 0,015 \\
\hline Framing* Exp. em Mktg & 0,675 & 01 & 2,911 & 0,091 \\
\hline Total & 61,000 & 120 & & \\
\hline
\end{tabular}

O procedimento ANOVA indicou a ocorrência do efeito framing no grupo total $(\mathrm{F}=4,35 ; \mathrm{p}=0,04)$. A investigação do efeito framing especificamente em cada um dos dois grupos - com e sem experiência na área de marketing - deurse através do cálculo da estatística t, que mede a diferença entre proporções. Analisando-se as respostas do grupo sem experiência, tem se que a participação percentual na escolha do produto Brastemp I é significativamente maior na versão com três opções de produtos do que na versão com duas $(\mathrm{t}=-4,32 ; \mathrm{p}=0,00)$. Já no grupo composto por profissionais de marketing, a participação percentual do produto Brastemp I nas duas situações acima mencionadas não apresentou diferença estatisticamente significativa $(\mathrm{t}=-0,37 ; \mathrm{p}=0,71)$, o que sugere que este grupo não deslocou sua percepção de referência mesmo com a adição de mais um produto à linha.

\section{CONCLUSÕES}

Os testes empíricos realizados neste estudo confirmaram a hipótese do efeito framing em todas as perguntas do questionário e corroboraram, portanto, no Brasil, com resultados obtidos nos Estados Unidos. A primeira pergunta do questionário manipulou a variável relativa a contexto de compra e induziu diferentes percepções sobre o custo do produto para o vendedor. Como resultado, diferentes valores foram fixados para o preço máximo a ser pago por um mesmo produto. A segunda pergunta testou, e confirmou, a proposta de que diferenças de preço são avaliadas de forma relativa e não absoluta. A terceira e quarta perguntas confirmaram, respectivamente, a noção de justiça e a influência da composição da linha de produtos a que o comprador está exposto na formação do preço de referência. As diferentes formulações dessas duas perguntas mostraram que vendedores podem fazer uso de tais considerações e enfatizar economias relativas ao preço de tabela, o qual funciona como preço de referência.

Uma segunda questão de interesse deste trabalho foi a de como reduzir o efeito framing e melhorar o processo decisório dos consumidores. Em relação a essa questão, é oportuno observar inicialmente que, até o momento, a literatura relativa à aplicação da Teoria das Perspectivas na área de Comportamento do Consumidor parece ter dado mais atenção a propostas de refinamento no desenvolvimento de táticas 
e estratégias de marketing (ver, por exemplo, Nagle e Holden, 1995 e 2002) do que a melhoria no processo decisório dos consumidores. Bazerman (2001), ao rever uma amostra significativa do Journal of Consumer Research, assinala: "Para minha surpresa, eu descobri que essa literatura tem sido significativamente silenciosa em relação a muitos dos mais importantes episódios de compra". Adiante, ele comenta: “... a maioria dos pesquisadores parece ter negligenciado consumidores até mesmo como uma audiência indireta de seu trabalho” (p.499).

A confirmação, parcial, da hipótese de que experiência gerencial em marketing tem impacto sobre a magnitude do efeito framing sugere que esforços no sentido de tornar o consumidor mais informado e consciente do seu processo decisório podem ter um impacto sobre as escolhas que ele faz. Uma interação abrangente e sistemática entre a pesquisa acadêmica e publicações que têm o consumidor como público-alvo nos parece igualmente relevante. Como Bazerman (2001) indica: "Eu acredito que pesquisas sobre consumidores têm falhado em transmitir a jornalistas insights úteis que possam ser repassados aos consumidores".

Algumas limitações importantes do estudo merecem atenção. Em primeiro lugar, conforme discutido na apresentação dos procedimentos experimentais, a amostra utilizada obedeceu a critérios de conveniência, em função da estrutura do experimento, não havendo a designação aleatória dos participantes do estudo entre as duas condições da variável relativa a experiência gerencial em marketing. Além disso, reconhecemos que o uso de experiência gerencial em marketing como definição operacional de experiência e conhecimento especializado em decisões de consumo possa ser questionado. Estudos futuros são necessários no sentido de investigar essa relação, para que se possa melhor avaliar até que ponto profissionais de marketing estão de fato mais bem treinados para tomar decisões de compra do que os demais consumidores. Outra limitação se refere ao uso de marcas na questão 4 do questionário, visando gerar a percepção de que o produto incluído na linha é de maior qualidade do que os demais. Sabe-se, no entanto, que as marcas podem gerar percepções e reações nas pessoas fora do controle do experimento.

A apresentação destas limitações aponta para o fato de que o presente estudo, de caráter inovador, pode ser considerado um embrião para pesquisas futuras nesta área, no meio acadêmico brasileiro. Considerações sobre possibilidade de pesquisas futuras partem do fato de que a quase totalidade dos estudos sobre efeito framing na percepção de preço e valor dos consumidores foi realizada nos EUA. Pesquisas com esta temática no contexto brasileiro podem gerar uma discussão profícua sobre o aspecto da diferença de ambiente sócio-econômico dos dois países. Desta forma, alguns temas que nos parecem relevantes para pesquisas futuras se referem a: 1. Avaliação de como diferentes estratégias de preço afetam a percepção de valor e a decisão de compra em diferentes tipos de produtos e serviços; 2 . De que forma a exposição do consumidor a conceitos de economia, estatística ou marketing faz com que este esteja menos suscetível ao efeito framing na tomada de decisão de compra. O aprofundamento destes temas poderá enriquecer os resultados encontrados neste estudo, ampliando o entendimento sobre as reações do consumidor brasileiro a preço e valor, no sentido de se contribuir para um aprimoramento no processo de tomada de decisão de compra.

\section{REFERÊNCIAS BIBLIOGRÁFICAS}

AVILA, M; COSTA, I. Tomada de Decisão: Um Teste da Teoria dos Prospectos. Anais do XX ENANPAD, 1996. 
MERCADOLOGIA - PERCEPÇÃO SOBRE PREÇO E VALOR: UM TESTE EXPERIMENTAL

Daniela Abrantes Serpa - Marcos Gonçalves Avila

BAZERMAN, H. Consumer Research for Consumers, Journal of Consumer Research, Vol.27, p. 499504, 2001.

Judgment in Managerial Decision Making, New York: John Wiley \& Sons, 1998.

DAWES, R. Rational Choice in an Uncertain World. Orlando: Harcout Brace Jovanovich, 1988.

FISCHHOFF, B. Debiasing, In D. Kahneman, P. Slovic and A.; Tversky, (Eds.), Judgment Under Uncertainty: Heuristics and Biases, Cambridge, Mass: Cambridge University Press, 1982.

HAIR, J. F.; ANDERSON, R. E.; TATHAM, R. L.; BLACK, W.C. Multivariate Data Analysis. New Jersey: Prentice-Hall, 1998.

KAHNEMAN, D.; KNETSCH, J.; THALER, R. Experimental Tests of the Endowment Effect and the Coase-Theorem. Journal of Political Economy, v. 98, p.1325-1348, 1990.

KAHNEMAN, D.; TVERSKY, A. Choices, Values, and Frames. American Psychologist, v. 39, no 4, p. 341-350, 1984.

p. 263-290, 1979.

Prospect Theory: An Analysis of Decision Under Risk. Econometrica, v. 47, n. 2,

KERLINGER, F. Metodologia da Pesquisa em Ciências Sociais, Um Tratamento Conceitual. Traduzido de Behavioral Research - A Conceptual Approach, São Paulo: EDUSP - Editora da Universidade de São Paulo, 1980.

KOTLER,P. Administração de Marketing: Análise, Planejamento, Implementação e Controle, São Paulo: Ed. Atlas, 1996.

LAMBERT, Z. V. Perceived Prices as Related to Odd and Even Price Endings. Journal of Retailing, v. 52, p. 13-22, 1975.

NACHMIAS, D.; NACHMIAS, C. Research Methods in the Social Sciences, New York: St. Martin Press, Third Edition, 1987

NAGLE, T. Entrevista à HSM Management, julho-agosto 2002, pp.66-71.

NAGLE, T.; HOLDEN, R. The Strategy and Tactics of Pricing. New Jersey, Prentice Hall, Third Edition, 2002.

NAGLE, T.; HOLDEN, R The Strategy and Tactics of Pricing. New Jersey, Prentice Hall, Second Edition, 1995.

PAGANO, R. R. Understanding Statistics In The Behavioral Sciences. St. Paul: West Publishing Company, 1986.

RUSSO, E.; SCHOEMAKER, P. Decision Traps. New York: Ed. Doubleday, 1989.

SIMON, H. Models of Man, New York: John Wiley, 1957 
SIMONSON, I. Get Closer to your Customers by Understanding How They Make Choices. California Management Review, pp. 68-84, 1993.

SIMONSON, I.; TVERSKY, A. Choice in Context: Tradeoff Contrast and Extremeness Aversion, Journal of Marketing Research, v. 29, p. 281-295, 1992.

SMITH, G. E.; NAGLE, T. T. Frames of Reference and Buyer's Perception of Price and Value. California Management Review, v. 38, no 1, p. 98-116, 1995.

THALER, R. Mental Accounting Matters, Journal of Behavioral Decision Making, v.12, p.183-206, 1999.

$214,1985$.

Mental Accounting and Consumer Choice. Marketing Science, v. 4, no 3, p. 199-

Toward a Positive Theory of Consumer Choice. Journal of Economic Behavior and Organization, v. 1, p. 39-60, 1980.

TVERSKY, A.; KAHNEMAN, D. The Framing of Decisions and the Psychology of Choice. Science, v. 211, p. 453-458, 1981.

URBANY, J. E.; BEARDEN, W. O. ; WEILBAKER, D. C. The Effect of Plausible and Exaggerated Reference Prices on Consumer Perceptions and Price Search. Journal of Consumer Research, v. 15, p. 95-110, 1988.

WASSON, R.; McCONAUGHY, D. H. Buying Behavior \& Marketing Decisions. New York: Meredith Corporation, 1968.

\section{Artigo recebido em 01.02.2002. Aprovado em 17.12.2003.}

\section{Daniela Abrantes Ferreira Serpa}

Doutoranda e Mestre em Administração pela COPPEAD/UFRJ.

Interesses de pesquisa: Comportamento do consumidor, decisões de preços, marketing de serviços,

E-mail: dabrantes@ coppead.ufrj.br

Endereço: Rua Nascimento Silva, 183 apto. 304 - Ipanema - Rio de Janeiro - RJ, 22421-020.

responsabilidade social corporativa.

\section{Marcos Gonçalves Ávila}

Professor Adjunto do COPPEAD/UFRJ. Ph.D. em Administração pe la New York University. M.Sc. em Administração pelo COPPEAD/UFRJ.

E-mail: marcos@coppead.ufrj.br

Endereço: Av. Epitácio Pessoa, 4344, B1. B, apto. 404 - Lagoa - Rio de Janeiro - RJ, 22471-001.

Interesses de pesquisa: processos de julgamento e tomada de decisão sob incerteza, comportamento do consumidor, decisões de preços, e organização de sistemas de custos. 